\title{
Thermodynamics of equilibrium states and approaches to analyzing the mass transport in metal-oxide systems
}

\author{
Olga V. Lavrova ${ }^{1}$, Aleksandr Yu. Legkikh ${ }^{1}$ \\ 1 JSC “SSC RF-IPPE n.a. A.I. Leypunsky”, Bondarenko Sq., Obninsk, Kaluga Reg., 249033 Russia \\ Corresponding author: Aleksandr Yu. Legkikh (alegkikh@ippe.ru)
}

Academic editor: Boris Balakin • Received 21 August 2019 • Accepted 5 September 2020 Published 20 November 2020

Citation: Lavrova OV, Legkikh AYu (2020) Thermodynamics of equilibrium states and approaches to analyzing the mass transport in metal-oxide systems. Nuclear Energy and Technology 6(4): 261-268. https://doi.org/10.3897/nucet.6.60300

\begin{abstract}
Analysis of corrosion processes has a major role in justifying the reliability and safety of developed nuclear reactors of a new generation with heavy liquid metal coolants. An approach has been developed which allows practical conclusions to be made with respect to the processes in the given metal-oxide system based on analyzing state diagrams for these systems in the "oxidation potential - temperature" coordinates. The proposed approach relies on a long-term experience of experimental and computational studies concerned with the interaction of various steel grades with molten lead and lead-bismuth, as well as with the transport of metal impurities within these molten metals. The oxidation potential of a metal-oxide system is measured in experimental studies using oxygen activity sensors developed and manufactured at IPPE. The applicability of the proposed approach to analyzing the processes of mass transport in iron-oxygen, lead-oxygen, sodium-oxygen, and iron-water vapor systems has been demonstrated.
\end{abstract}

\section{Keywords}

State diagram, iron, liquid metal coolant, oxygen, corrosion, metal-oxide system, oxidation potential, equilibrium pressure

\section{Introduction}

One of the most important processes that define the stability of solid materials in various environments is oxidation of solid metals by the environment components with a different degree of corrosive activity, specifically, oxygen corrosion of steels in heavy liquid metal coolants (lead or lead-bismuth). There is an extensive experimental and theoretical matter on oxidation of materials in gas environments (Shimansky et al. 2009, Nechaev et al. 2007, Kubaschewski and Hopkins 1965) which is, however, hard to adapt to processes taking place at the interface of a solid metal and a liquid metal containing dissolved oxygen since the role of liquid metal as such in the oxidation process is not quite understood.
The interaction of chemical substances is investigated, as a rule, from two points of view: analyzing the probability of any reactions to take place (thermodynamics) and the resultant reaction rate (kinetics). Thermodynamics, as the general reaction direction, is estimated at a qualitative level based on constants shown in handbooks (Uiks 1965, Veryatin et al. 1965, Kulikov 1986), and kinetics is investigated experimentally with the finish equation obtained which links the oxidation rate to time and external conditions (metal kind, temperature, oxidizer pressure, etc.).

Sodium coolant is known to be less corrosive with respect to steel components than lead-based coolants. This is explained by the low solubility of iron in sodium (Subbotin et al. 1970) and the processes of steel degradation in sodium are associated with the carbon lost by steel and

* Russian text published: Izvestiya vuzov. Yadernaya Energetika (ISSN 0204-3327), 2020, n. 2, pp. 39-51. 
by formation of complex chromic sodium oxides in the intergranular space of steels (Alekseev et al. 2015).

In contrast, increased corrosive activity of lead-based coolants, as compared with alkali metals, is explained by the increased solubility of iron in these coolants which provides for anisothermic transport of iron from the hot zone of the circulation circuit to the cold zone (Handbook 2015, Askhadullin et al. 2016).

Corrosion of steels in water coolant is explained by the electrochemical transport of the substance, which was first shown by Wagner (Bagotsky 1988) whose works are referred to by later authors, e.g. in (Lineckij et al. 1985), while noting, among other things, the divergence of the experimental data and the calculation results due to polarization.

This paper presents a thermodynamic approach to analyzing the processes taking place at different phase boundaries based on calculating the electrical potentials of these boundaries being in equilibrium with oxygen. This approach was demonstrated using the comparative characteristics of the corrosive behavior of the following systems used as coolants in nuclear power plants:

- lead-oxygen;

- iron - oxygen;

- sodium - oxygen;

- water vapor - oxygen.

The corrosive behavior of coolants has been shown to be defined, among other things, by the difference in the electrical potentials forming at the interfaces of steels (primarily irons) and the coolant.

\section{Thermodynamics and electrical potential of stoichiometric oxides}

It was practically at the very beginning of the lead-bismuth coolant adoption that investigators understood the substantial effect the dissolved oxygen concentration in lead-based melts had on the corrosion of steel components, and equipment was built for the continued observation of this quantity variation.

Oxygen activity sensors (OAS) for lead-bismuth coolants were developed at IPPE under the leadership of B.A. Shmatko which were further used in lead coolant circuits as well (Gromov and Shmatko 1996).

The difference of the potentials between the coolant and the reference electrode is determined by the wellknown Nernst equation:

$\Delta E(B)=-\frac{\Delta G_{T}}{z \cdot F}=\frac{\left(\Delta G^{\text {ref.el }}-\Delta G^{\text {envir. }}\right)}{z \cdot F}=\frac{R T\left(\ln p_{O 2}^{\text {ref.el. }}-\ln p_{O 2}^{\text {envir. }}\right)}{4 \cdot F}$,

where $p_{\mathrm{O} 2}^{\text {ref.el }}$ is the equilibrium partial pressure of oxygen over the metal-oxide system selected as the reference electrode; $p_{\mathrm{O} 2}^{\text {envir. }}$ is the equilibrium partial pressure of oxygen over the coolant containing dissolved oxygen; $R$ is the universal gas constant; $T$ is the temperature, $\mathrm{K}$; and $F$ is the Faraday constant.

The $\{\mathrm{Bi}\}-<\mathrm{Bi}_{2} \mathrm{O}_{3}>$ system, the oxidation potential $\left(p_{\mathrm{O}_{2}}\right)$ of which is calculated by the Gibbs equation using thermodynamic data, is used most often as the reference electrode (zero potential) (Kulikov 1986):

$$
\lg p_{O 2}^{\{B i\}<<B i_{2} O_{3}>}=-\frac{20609}{T}+10.188 .
$$

We shall use the same system of coordinates to calculate the electrical potentials of various media as well.

The measured electrical signal with the known temperature in the OAS vicinity is easily converted to the values of the oxygen concentration in the coolant $\left(C_{\mathrm{O}}\right)$ (Askhadullin et al. 2016, Gromov and Shmatko 1996). A system of several oxygen sensors can be installed at any points of the liquid metal coolant circulation circuit. Examples of the OAS EMF behavior depending on time or the temperature at the installation point can be found in a number of publications, e.g. in (Askhadullin et al. 2016, Martynov et al. 2009).

Despite the fact that the actual OAS signal is an electrophysical quantity, investigators normally associate it only with the concentration of oxygen in the coolant. At the same time, the sensor measured electrical potential $\Delta E$ exists in the melt irrespective of if it is measured or not. Moreover, different values of $\Delta E$ can be simultaneously recorded at different melt points using several sensors. The divergences in the $\Delta E$ values in steady-state facilities may amount to $\sim 100 \mathrm{mV}$, and those in anisothermic forced circulation circuits in certain modes reach $\sim 300 \mathrm{mV}$.

As it follows from electrochemistry laws (Damaskin et al. 2006), an electromotive force, which has a particular direction, arises and, according to Faraday laws, causes the cations and anions to move towards each other if a difference occurs in the electrochemical potentials between two space points. If the conditions at each of these points are known, it is not difficult to calculate the difference in the electrical potentials or the force acting on the cations and anions.

From this point of view, we shall consider in the $\Delta E(\mathrm{t})$ coordinates the relative position of some stable oxide systems which may form in response to the contact of the coolant $\left(\mathrm{Pb}, \mathrm{Na}, \mathrm{H}_{2} \mathrm{O}\right)$ and iron, as the base component of structural steels, with oxygen. This will make it possible to evaluate the movement direction of various metal ions and to detect possible equipment corrosion mechanisms. In this case, coolants act as the environment for solid iron (steel) or its oxide.

\section{Lead-oxygen system}

The nature of the $\mathrm{Pb}-\mathrm{O}$ system behavior depending on the oxygen potential level has been well studied experimentally. So it is this system that the analysis should be reasonably started with. The calculations are based on the Gibbs energy from the solid lead monoxide formation reaction (Kulikov 1986): 


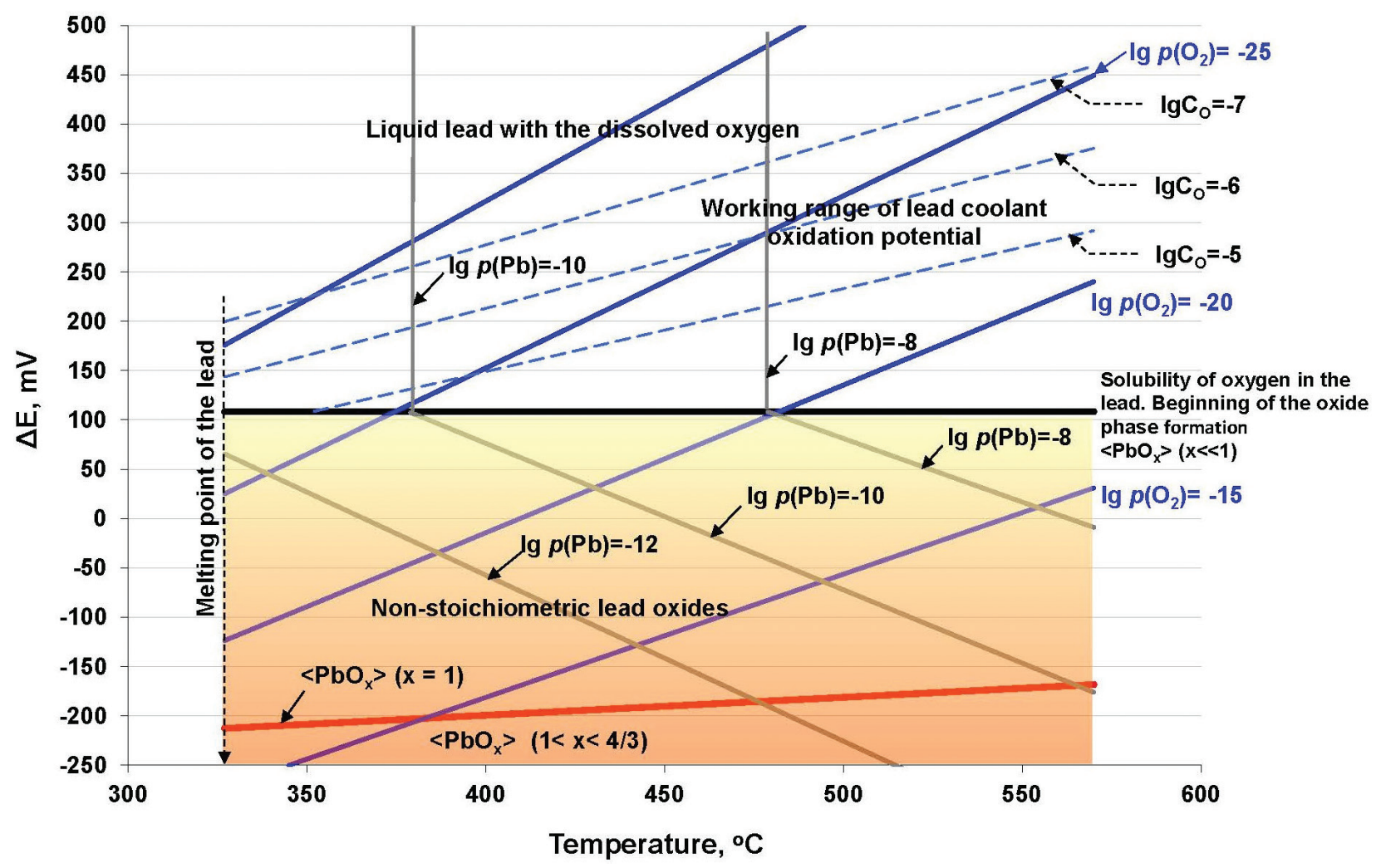

Figure 1. $\Delta E-t$ diagram of the molten lead state in terms of oxygen impurity relative to the $\{\mathrm{Bi}\}-<\mathrm{Bi}_{2} \mathrm{O}_{3}>$ system potential.

$$
\{\mathrm{Pb}\}+1 / 2\left(\mathrm{O}_{2}\right)=<\mathrm{PbO}>\text {. }
$$

For the conditions of equilibrium achieved after the reaction is over, the constancy of the ratio of the reaction product activities and the residual activities of reagents is fulfilled:

$$
k_{(3)}=\frac{a_{\{P b O\rangle}}{a_{\{P b\}} \cdot a_{(O 2)}^{1 / 2}} \text { or } k_{(3)}=\frac{1}{\frac{p_{(P b)}}{p_{(P b)}^{\circ}} \cdot p_{\left(O_{2}\right)}} .
$$

Depending on the temperature and the initial mole ratio of pure reagents, equilibrium can be reached at any value $p_{\mathrm{O}}$, which, in the $\Delta E(\mathrm{t})$ coordinates, corresponds to one diagram point. Let us assume that we know in advance (or have measured or defined) that there is a certain equilibrium partial pressure of oxygen at the preset temperature.

It follows from equation (4) that only one metal activity value corresponds to this oxygen pressure. If it turns out as the result of a formal calculation that $a_{P b} \approx 1$, this metal is present in the system as a phase (condensate). If $a_{P b}<1$, then there is no metal phase under the given conditions; the metal is expected to transform fully into oxide with any content of oxygen.

Diagram of Fig. 1 presents calculated electrical potentials of the $\mathrm{Pb}-\mathrm{O}$ system depending on temperature. As can be seen, the system in this temperature interval is divided into two major regions.

The upper region is characterized by the lead activity values which are close to unity $\left.a_{(\mathrm{Pb})}=p_{(\mathrm{Pb})} / p_{(\mathrm{Pb})}^{\circ} \approx 1\right)$. This is therefore the liquid lead existence region. The limiting state of the liquid lead existence is the potential shown by the black line (practically a horizontal). Oxygen additions to such a system do not practically affect the potential value since its activity is kept at the level of unity until there is no more lead.

With regard for the reference data for $\Delta G^{\circ}{ }_{T}$ (Kulikov 1986), using the expression for determining the equilibrium constant for the reaction $\ln k=-\mathrm{D} G_{T}^{\circ} /(R \cdot T)$, as well as with regard for (4), with $a_{(\mathrm{Pb})}=1$, we shall get:

$$
\lg p_{O_{2}}^{\{\mathrm{Pb}\}-<P b O\rangle}=-\frac{22726}{\mathrm{~T}}+10.1747 .
$$

The conversion of calculated values (5) using formula (1), with regard for (2), makes it possible to calculate the position of the equilibrium $\Delta E(\mathrm{t})$ as shown in Fig. 1.

Formal equilibrium (5) will be maintained on the metal and gas phase interface until there is no more metal phase. And, contrarily, where a constant partial pressure of oxygen is kept over the lead at level (5), there is no formally reaction between the gas phase and the liquid phase.

The higher is the $\Delta E$ value in the upper region, the smaller is the content of dissolved oxygen in lead and the lower is the partial oxygen pressure over this solution. This follows from an analysis of the positions of different oxygen isobars and the isoconcentration distribution of the oxygen dissolved in lead.

According to (1), the position of the oxygen isobars $\left(\operatorname{lgp}\left(\mathrm{O}_{2}\right)=\right.$ const $)$ in the $\Delta E(\mathrm{t})$ diagram is defined only by the reference electrode and does not depend on the kind of 
the metal interacting with oxygen. Fig. 1 presents the positions of the oxygen isobars $\lg \mathrm{p}\left(\mathrm{O}_{2}\right)=-15 ;-20 ;-25 ;-30$.

The positions of the isoconcentration lines (dashed straight lines) for oxygen $\left(\lg C_{\mathrm{O}}=\right.$ const $)$ have been calculated with regard for the limiting solubility of oxygen in liquid lead $C_{\mathrm{O}}^{\mathrm{S}}$ (Handbook 2015) and for the connection of the oxygen concentration and partial pressure:

$$
a_{O}=\frac{C_{O}}{C_{o}^{S}}=\frac{p_{o}}{p_{O}^{S}}=\sqrt{\frac{p_{O_{2}}}{p_{O_{2}}^{S}}} .
$$

That the position of the calculated region of the liquid lead oxidation potentials corresponds to the experimental data obtained during the measurement of this potential in molten lead is confirmed by many studies a fragment of which is presented in Fig. 1.

The lower region is characterized by the values of the lead activity $a_{P b}<1$ and is, therefore, the existence region of lead oxides with different oxygen contents.

The position of stoichiometric lead monoxide in the $\Delta E-t$ diagram is defined by the equilibrium of the lead monoxide dissociation reaction:

$$
<\mathrm{PbO}>\leftrightarrow(\mathrm{Pb})+1 / 2\left(\mathrm{O}_{2}\right)
$$

The energy of the solid lead oxide thermal dissociation reaction differs from the energy of the lead oxide formation primarily in quantitative characteristics: no condensed lead can be obtained from lead oxide by thermal dissociation. Just a small portion of oxygen and lead passes into the gas phase as the result of reaction (7). The electrical potential of lead monoxide corresponds to the level shown in Fig. 1: $<\mathrm{PbO}_{\mathrm{x}}>(\mathrm{x}=1)$. The calculation of the equilibrium for reaction (7) is based on determining the minimum of the total pressure in a closed system that defines the stable lead monoxide position (Kulikov 1986), and makes:

$$
\lg p_{\mathrm{O} 2}^{<\mathrm{PbO}>}=-\frac{14206}{\mathrm{~T}}+6.6555
$$

Therefore, in accordance with Fig. 1, the lead monoxide phase has an electrical potential that differs from the electrical potential of lead saturated with dissolved oxygen practically by $300 \mathrm{mV}$. This means that no lead monoxide of a red or yellow modification can form in a closed system when reaction (3) is equilibrium in the presence of liquid lead. However, with the partial oxygen pressure being at the level described by equation (5), the partial pressure limit for gaseous complexes $(\mathrm{PbO})$ is reached, from which gaseous polymers $(\mathrm{PbO})_{\mathrm{n}}(\mathrm{n}=1-4)$ form as new oxygen is added, and then a solid oxide phase forms by way of their condensation (Kulikov 1986). Limiting partial pressures of all gaseous polymers are reached at the equilibrium level described by equation (8).

An increase in the partial oxygen pressure over the lead monoxide phase in the respective temperature range leads to the lead monoxide gradual enrichment with oxygen up to the red lead $\left(<\mathrm{Pb}_{3} \mathrm{O}_{4}>\right)$ formation (not shown in Fig. 1).
The positions of the lead isobars $\lg \mathrm{p}(\mathrm{Pb})=$ const shown in Fig. 1 are calculated with regard for equations (1), (2), and (4), as well as for the equation for the lead pressure limit calculation (interpolation of data (Glushko 1978 ) in the temperature range of 600.5 to $1000 \mathrm{~K}$ ).

$$
\lg p_{\mathrm{Pb}}^{\circ}=-\frac{9745,2}{\mathrm{~T}}+4.9578 .
$$

By analogy with the diagram's upper region, the content of oxygen in an oxide phase in the lower region decreases as the value $\Delta E$ increases, and grows as $\Delta E$ decreases.

F.A.C.T. data (FACT 2020) confirms the correspondence of the partial oxygen pressure over lead monoxide to equation (8).

A positive difference in the electrical potentials between liquid lead and solid oxide $(<\mathrm{PbO}>)(\geq 300 \mathrm{mV})$ ensures that a spontaneous process of oxide dissolution in metallic lead takes place due to the countermovement of lead cations and oxygen anions. This reaction will evidently continue until the electrical potentials equalize throughout the closed system or equilibrium is reached.

\section{Iron-oxygen system}

The iron-oxygen diagram is calculated using data on the variation of the standard Gibbs potential for reactions of the solid iron oxide formation of solid iron and oxygen gas. The diagram's lower temperature limit is the lead melting point $\left(327.5^{\circ} \mathrm{C}\right)$. The maximum temperature limit for this system is $570{ }^{\circ} \mathrm{C}$. As shown by numerous studies, there is no wustite phase (iron oxide with the composition close to $\langle\mathrm{FeO}>$ ) found below this temperature which makes the calculation volume somewhat smaller.

The key reference data to calculate the equilibrium of the magnetite and hematite dissociation reactions is given in (Kulikov 1986). For guidance as to the oxidation potential level, the same diagram includes the equilibrium position for the $\{\mathrm{Pb}\}-<\mathrm{PbO}>$ reaction.

The diagram in Fig. 2 presents the Fe-O system in the same coordinates. An analysis of the diagram shows that the $<\mathrm{Fe}>-<\mathrm{Fe}_{3} \mathrm{O}_{4}>$ system is similar to the previous diagram as far as the presence of two phase regions is concerned:

- above the $<\mathrm{Fe}>-<\mathrm{Fe}_{3} \mathrm{O}_{4}>$ line - solid iron phase;

- below the $<\mathrm{Fe}>-<\mathrm{Fe}_{3} \mathrm{O}_{4}>$ line - solid iron oxide phase the composition of which depends on the oxidation potential of the environment.

The equilibrium of the reaction of the magnetite formation of iron and oxygen:

$$
3<\mathrm{Fe}>+2\left(\mathrm{O}_{2}\right)=<\mathrm{Fe}_{3} \mathrm{O}_{4}>
$$

is described by the equation $(<843 \mathrm{~K})$ :

$$
\left.\lg p_{\mathrm{O}_{2}}^{\mathrm{s}}\right|_{\left\langle\mathrm{Fe}><\mathrm{Fe}_{3} \mathrm{O}_{4}\right\rangle}=-\frac{28795}{\mathrm{~T}}+8.2508 .
$$




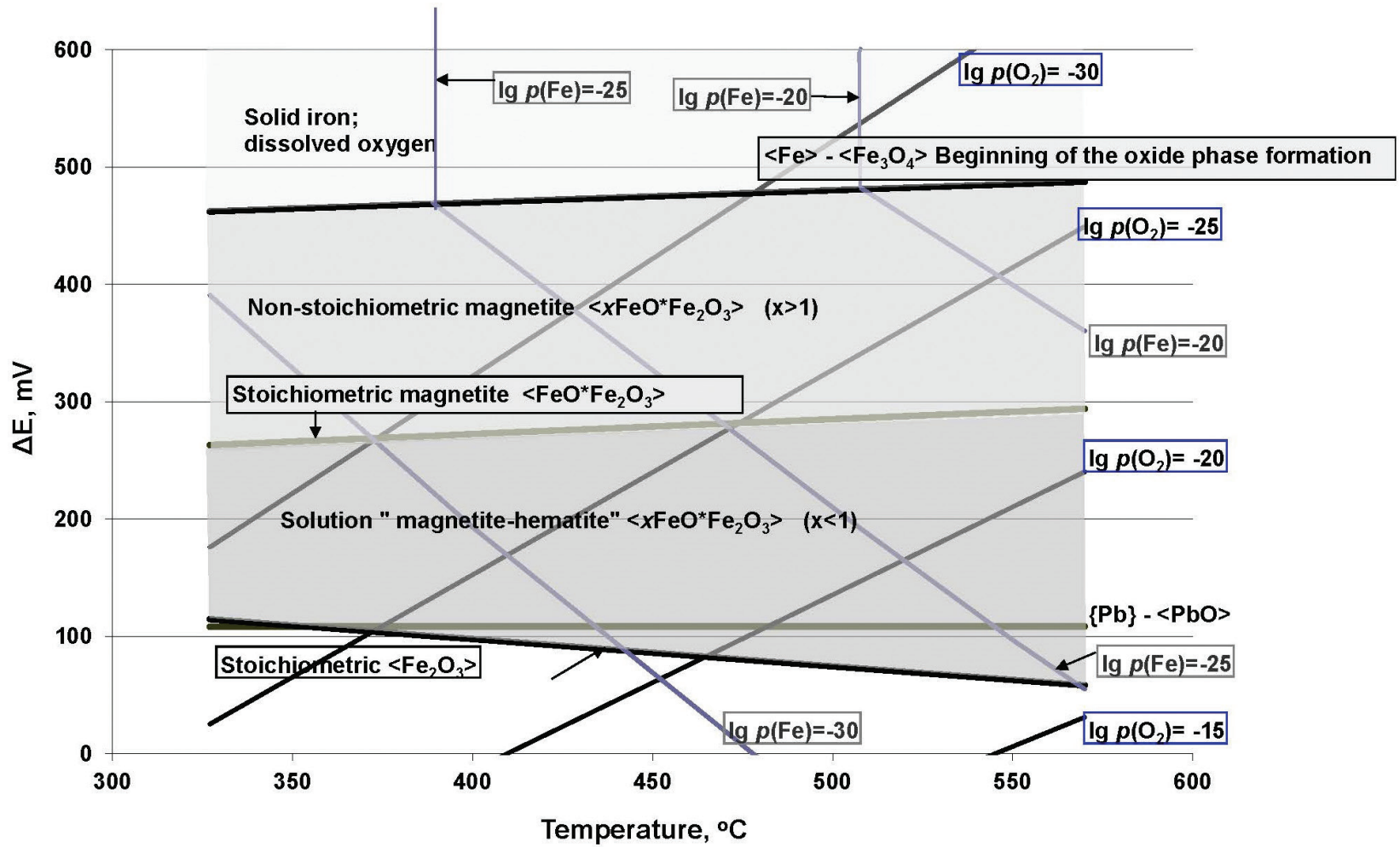

Figure 2. Iron-oxygen $E-t$ diagram relative to the $\{\mathrm{Bi}\}-<\mathrm{Bi}_{2} \mathrm{O}_{3}>$ system potential. The region above the $<\mathrm{Fe}>-<\mathrm{Fe}_{3} \mathrm{O}_{4}>$ line is solid iron with dissolved oxygen [FeO]. The region below the $<\mathrm{Fe}>-<\mathrm{Fe}_{3} \mathrm{O}_{4}>$ line is iron oxides with nonstoichiometric and stoichiometric compositions.

Oxidation potential (11) should be maintained at the iron - iron oxide interface until the iron phase passes fully into the oxide phase.

The equilibrium of the solid iron evaporation reaction:

$$
<\mathrm{Fe}>\leftrightarrow(\mathrm{Fe})
$$

is described by equation (FACT 2020):

$$
\lg p_{(\mathrm{Fe})}^{\circ}=-\frac{21658}{\mathrm{~T}}+7.5993 .
$$

The iron isobars in the diagram in Fig. 2 are diagonal straight lines with a negative temperature gradient.

The position of the oxygen isobars in Fig. 2 corresponds exactly to their position in any other metal-oxide system, e.g. in $\mathrm{Pb}-\mathrm{O}$ (Fig. 1).

The position of stoichiometric magnetite in the diagram was determined with regard for the equilibrium of the reaction of its dissociation (Kulikov 1986) by way of determining the minimum cumulative pressure for all gas phase components $\left(\mathrm{O}_{2}\right) ;(\mathrm{O}),(\mathrm{Fe}),(\mathrm{FeO})$ :

$$
\begin{gathered}
<\mathrm{FeO} \cdot \mathrm{Fe}_{2} \mathrm{O}_{3}>\leftrightarrow 3(\mathrm{Fe})+2\left(\mathrm{O}_{2}\right) \\
\left.\lg p_{(\mathrm{O} 2)}\right|_{<\mathrm{FeO} \cdot \mathrm{Fe}_{2} \mathrm{O}_{3}>}=-\frac{24221}{\mathrm{~T}}+7.428
\end{gathered}
$$

Keeping in the environment (e.g. in lead) the constant conditions characterized by the oxygen partial pressure values between levels (11) and (14) will lead to the formation of nonstoichiometric iron oxides with an increased content of ferrous iron relative to stoichiometric magnetite, $<\mathrm{nFeO} \cdot \mathrm{Fe}_{2} \mathrm{O}_{3}>(\mathrm{n}>1)$. And there is its own oxide composition that can be determined by calculation corresponding to each diagram point characterized by a pair of values $\left(T, p_{\mathrm{O}}\right)$.

The position of stoichiometric hematite is defined by the equilibrium partial pressure of oxygen during its dissociation (JANAF 1971, Tamm and Tretyakov 2004):

$$
\begin{aligned}
& <\mathrm{Fe}_{2} \mathrm{O}_{3}>\leftrightarrow 2(\mathrm{Fe})+3 / 2\left(\mathrm{O}_{2}\right) \\
& \left.\lg p_{\left(O_{2}\right)}\right|_{<\mathrm{Fe}_{2} \mathrm{O}_{3}>}=-\frac{25785}{T}+14.86
\end{aligned}
$$

Therefore, the diagram in Fig. 2 can be considered as a low-temperature part of the iron - oxygen system phase diagram in specific coordinates. However, the condensed iron position shown in the phase diagram by a straight vertical line $\left(C_{F e}=\right.$ wt. $\left.100 \%\right)$ turns, in these coordinates, into a region the potential of which depends on the temperature and the content of dissolved oxygen (by analogy with the oxygen solution in lead).

The compilation of the diagrams presented in Figs. 1 and 2 shows that the oxidation potential region between the levels $\sim 110 \mathrm{mV}<\Delta E<\sim 480 \mathrm{mV}$ is:

- the existence region of solid oxides with different compositions (for iron); 


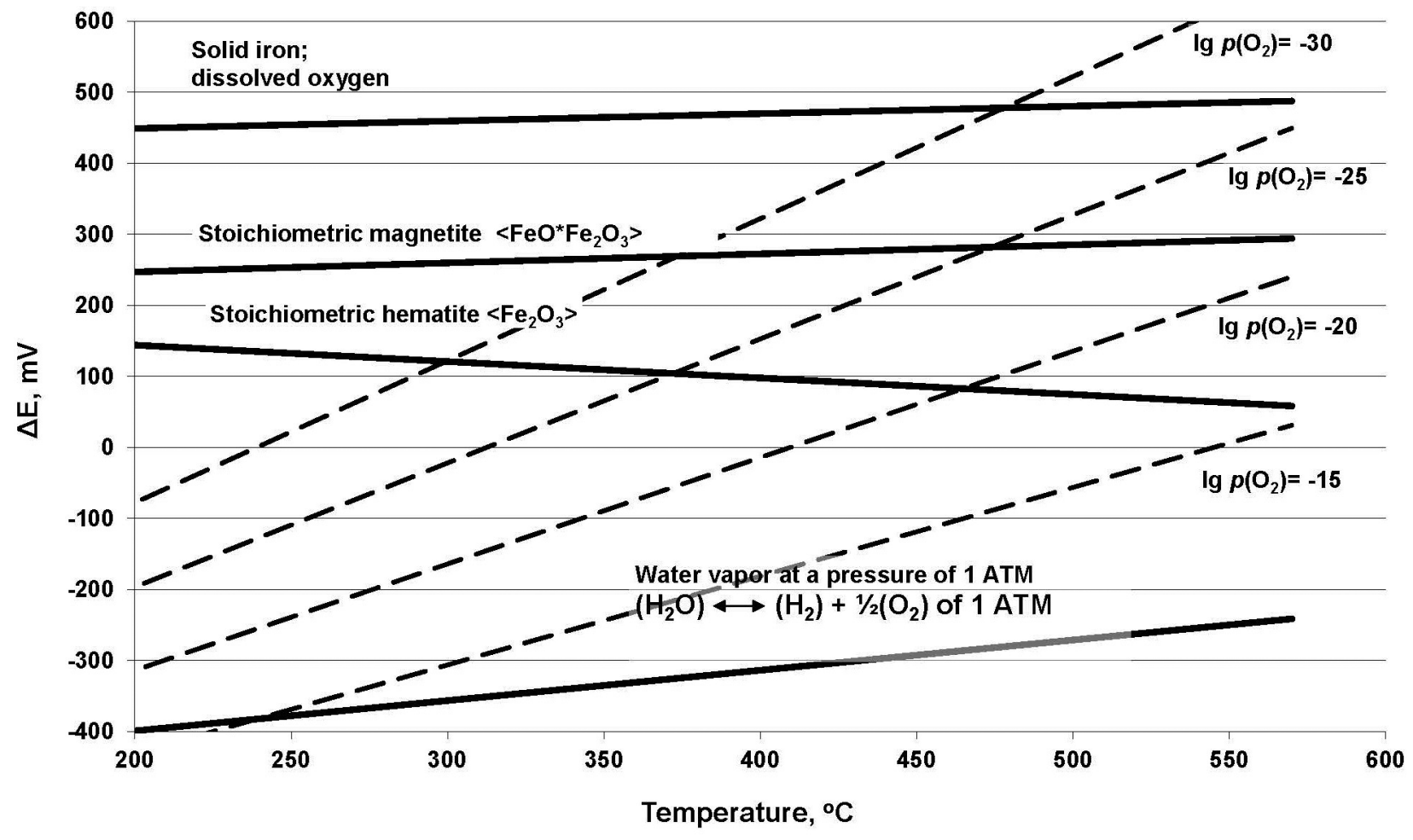

Figure 3. Iron - oxygen $E-t$ diagram and the water vapor position relative to the $\{\mathrm{Bi}\}-<\mathrm{Bi}_{2} \mathrm{O}_{3}>$ system potential.

- the existence region of the liquid metal phase containing dissolved oxygen (for lead).

Consequently, the role of lead in the process of iron oxidation by oxygen is explained primarily by the limits of the oxidation potential values. Gaseous mixtures like $\left(\mathrm{H}_{2}\right)$ $-\left(\mathrm{H}_{2} \mathrm{O}\right)$ or $(\mathrm{CO})-\left(\mathrm{CO}_{2}\right)$ used in metallurgy for keeping the required oxidation potential of the environment may also have a similar role.

Therefore, there is a positive difference of the potentials maintained at all times between the solid iron phase (steel) and the liquid lead phase with dissolved oxygen which provides for the transport of iron ions from the iron phase, where the oxidation potential is small, into the molten lead volume where the oxidation potential is much higher. It is exactly this force that accounts for the corrosion of steels in lead or lead-bismuth coolant.

It follows from the diagram in Fig. 2 that the composition of the external oxide film layer will be different on one and the same steel tested with an identical oxygen concentration but with various temperatures, since the oxide composition depends on the pair of values $\left(T, p_{\mathrm{O}_{2}}\right)$ which are different for various circuit points. Besides, hematite, the highest oxide of iron, cannot form in the region of the used oxygen concentrations in lead coolant.

It needs to be noted that the presence of structural steels, on the one hand, and the entry of oxygen into molten lead, on the other hand, keep the non-equilibrium state (and, therefore, the chemical interaction) of the system and, consequently, the transport of components normally to the steel surface.

\section{Water vapor}

Water vapor of $1 \mathrm{~atm}$ has been selected as the reagent for estimating the oxidation potential of water coolant. Estimates for the water vapor dissociation are presented (not to be confused with the water formation reaction) in the diagram in Fig. 3.

$$
\left(\mathrm{H}_{2} \mathrm{O}\right) \leftrightarrow\left(\mathrm{H}_{2}\right)+1 / 2\left(\mathrm{O}_{2}\right)
$$

The calculation of the partial pressure of oxygen in equilibrium with water vapor at 1 atm was taken from (Kulikov 1986) and interpolated in a range of 298 to 1000 $\mathrm{K}$ by the equation

$$
\lg p_{\mathrm{O} 2}=-\frac{8500,6}{\mathrm{~T}}+1.5967 .
$$

For comparison, the same diagram in Fig. 3 presents the iron - oxygen system.

Without giving a detailed analysis of the iron interaction with water vapor, we shall note that the difference in the electrical potentials between system (15) and the $\mathrm{Fe}-\mathrm{O}$ system is also positive which provides for the flow of iron into the environment, that is, into water vapor. However, the level of the water vapor oxidation potential allows it to co-exist with hematite, the highest oxide of iron, which has as small permeability parameters as possible, both in terms of oxygen and iron, and good passivating properties. Due to this, water coolants are less corrosive with respect to structural materials than leadbased coolants. 


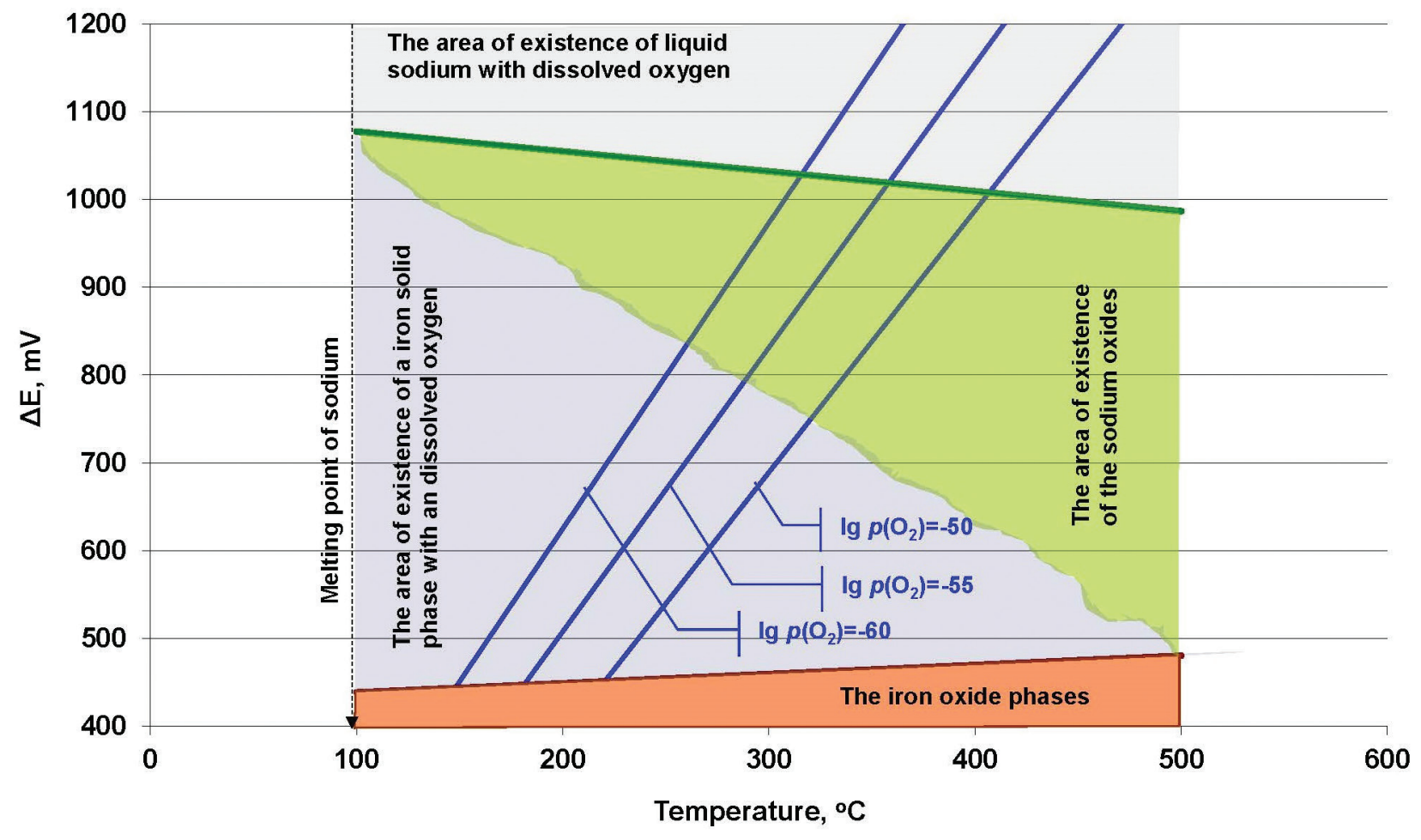

Figure 4. Sodium - oxygen and iron - oxygen $E-t$ diagrams relative to the $\{\mathrm{Bi}\}-<\mathrm{Bi}_{2} \mathrm{O}_{3}>$ system potential.

Hematite is known to be the highest oxide of iron. If a larger oxidation potential is maintained in the environment, then an electrical field, which compensates for the difference in the potentials between the hematite surface and the environment (e.g., the adsorption layer), is expected to form at the interface. If a smaller oxidation potential is maintained in the environment, an oppositely directed electrical field is expected to form at the interface, and the solid surface will turn to be electrically charged due to the environment lacking elements to compensate for this charge (up to an equilibrium achieved with the environment).

\section{Sodium-oxygen system}

Fig. 4 presents relative positions of electrical potentials in the sodium - oxygen system and in the iron - oxygen system.

The level of the $\{\mathrm{Na}\}-<\mathrm{Na}_{2} \mathrm{O}>$ system's electrical potential or liquid sodium in the oxygen saturation conditions corresponds to $\sim 1000 \mathrm{mV}$ :

$$
\left.\left.\operatorname{lgp}\right|_{\left(\mathrm{O}_{2}\right)}\right|_{\left\{\mathrm{Na}_{2}\right\}-<\mathrm{Na}_{2} \mathrm{O}>}=-\frac{44036}{\mathrm{~T}}+14.761 .
$$

The oxidation potential of the stoichiometric oxide $<\mathrm{Na}_{2} \mathrm{O}>$ is calculated by equation (Kulikov 1986):

$$
\operatorname{lgp}\left(\mathrm{O}_{2}\right)_{<\mathrm{Na}_{2} \mathrm{O}>}=-\frac{13050}{\mathrm{~T}}+6.192,
$$

which corresponds to the electrical potential at the level $(-300)-(-220 \mathrm{mV})$. This means that such oxide with the composition $<\mathrm{Na}_{2} \mathrm{O}>$ cannot exist in equilibrium with liquid sodium.
The existence region of nonstoichiometric sodium oxides with a smaller content of oxygen coincides with the solid iron phase existence region with a different oxygen saturation degree. There cannot be iron oxides in this region of potentials. This is confirmed in practice: there are no iron-based oxide films on the structural materials being in contact with sodium (Kinev et al. 2017).

The existence region of liquid sodium with any content of dissolved oxygen corresponds to a higher electrochemical potential than required for the existence of iron oxides. That is, the electrical charge of the oxygen saturated iron phase in the system under consideration is negative with respect to liquid sodium.

Such difference in electrical potentials is capable to provide for the movement of sodium ions into the iron phase to form a compound with the oxygen contained in iron rather than contrarily. It is exactly for this reason that there is no iron cation mass transport into sodium.

\section{Conclusion}

The authors have proposed an approach to determining the direction of mass transport (specifically of iron as the base component of steels) in metal-oxide systems based on a comparative thermodynamic analysis of the reactions taking place which is presented in the electrical potential - temperature coordinates.

Potential interactions within the iron - oxygen - coolant systems have been considered. Lead, water vapor, and sodium in the temperature region of up to $570{ }^{\circ} \mathrm{C}$ have been considered as the coolant. 
It has been shown that a positive difference in the electrical potentials between the iron phase and the lead phase in the presence of oxygen provides for the transport of iron cations into the coolant and for the formation of stoichiometric hematite at the interface of nonstoichiometric magnetite the composition and, therefore, permeability of which depend on the temperature and content of oxygen in lead.

\section{References}

- Alekseev VV, Kozlov FA, Sorokin AP, Varseev EV, Orlova EA, Torbenkova IY (2015) Mass transfer of corrosion products and corrosion of steel in sodium at high hydrogen concentrations. Teploenergetika 10: 72-80. https://doi.org/10.1134/S0040601515100018 [in Russian]

- Askhadullin RS, Martynov PN, Rachkov VI, LegkikhAYu, Storozhenko AN, Ul'yanov VV, Gulevskiy VA (2016) Monitoring and control of the oxygen content in heavy liquid-metal coolants for anticorrosion protection of steels. Teplofizika Vysokikh Temperatur 54(4): 564-572. https://doi.org/10.1134/S0018151X16040015 [in Russian]

- Bagotsky VS (1988) Fundamentals of electrochemistry. Moscow. Khimiya Publ., 400 pp. [in Russian]

- Damaskin BB, Petrij OA, Cirlina GA (2006) Electrochemistry. Moscow, Khimiya Publ., 672 pp. [in Russian]

- FACT (2020) Facility for the analysis of chemical thermodynamics. http://www.cret.polymtl.ca/fact [accessed Aug 15, 2019].

- Glushko VP (1978) Thermodynamic properties of the individual substances. Moscow, Nauka Publ., 496 pp. [in Russian]

- Gromov BF, Shmatko BA (1996) Physical and chemical properties of lead-bismuth melts. Izvestiya vuzov. Yadernaya Energetika 4: 35-41. [in Russian]

- Handbook on lead-bismuth eutectic alloy and lead properties (2015) Materials compatibility, Thermalhydraulics and technologies. OECD/NEA, no. 7268, 950 pp.

- JANAF Thermochemical Tables (1971) Sec. NBS USA, Washington, $1100 \mathrm{pp}$.

- Kinev EA, Pastuhov VI, Glushkova NV (2017) Liquid-metal corrosion of cladding steel in sodium coolant. VANT. Ser.: Yaderno-Reaktornye Konstanty 3: 80-86. [in Russian]

- Kubaschewski O, Hopkins B (1965) Oxidation of metals and alloys. Moscow, Metallurgy Publ., 428 pp. [in Russian]
A positive difference of potentials between the iron phase and water vapor also provides for the mass transport of iron cations with hematite of a smaller permeability than magnetite enriched with ferrous iron formed however at the interface as the reaction product.

A negative difference of potentials between the iron phase and oxygen saturated sodium hampers the iron mass transport into the sodium coolant.
Kulikov IS (1986) Thermodynamics of oxides. Moscow, Metallurgy Publ., 344 pp. [in Russian]

- Lineckij BL, Krupin AV, Opara BK, Rakoch AG (1985) Oxidation5 free heating of rare metals and alloys in vacuum. Moscow, Metallurgy Publ., 184 pp. [in Russian]

- Martynov PN, Askhadullin RSh, Simakov AA, Chaban' AYu, Chernov ME, Lanskikh VS, Legkih AYu (2009) Creation of automatic system for monitoring, forecasting and control of condition of lead-bismuth (lead) coolant and surfaces of circuits of nuclear power plants. In: Proceedings of the XVII ${ }^{\text {th }}$ International Conference on Nuclear Engineering (ICONE17), July 12-16. Brussels, Belgium, 549-554. https://doi.org/10.1115/ICONE17-75504

- Nechaev VV, Smirnov EA, Kohtev SA, Kalin BA, Polyansky AA, Statsenko VI (2007) Fundamentals of materials science. Volume 2. Moscow, MEPhI Publ., 608 pp. [in Russian]

- Shimansky AF, Belousova NV, Vasilieva MN (2009) Physics and chemistry of inorganic materials. Course of lectures. Krasnoyarsk, IPK SFU Publ., 204 pp. [in Russian]

- Subbotin VI, Ivanovsky MN, Arnoldov MN (1970) Physical and chemical bases of the liquid metal coolants application. Moscow, Atomizdat Publ., 296 pp. [in Russian]

- Tamm ME, Tretyakov YuD (2004) Physical and chemical bases of inorganic chemistry: Textbook for students. Moscow. Publishing center "Akademiya", 240 pp. [in Russian]

- Uiks KE (1965) Thermodynamic properties of 65 elements - their oxides, halides, carbides, and nitrides. Moscow, Metallurgiya Publ., 240 pp. [in Russian]

- Veryatin UD, Mashirev VP, Ryabcev NG, Tarasov VI, Rogozkin BD, Korobov IV (1965) Thermodynamic properties of the inorganic substances. Moscow, Atomizdat Publ., 460 pp. [in Russian] 